\title{
The use of Crushed Ceramic Waste as Granular Corrector in the Manufacture of the Mortars Based on Dune Sand
}

\author{
Ghrieb Abderrahmane ${ }^{1,2, *}$ and Abadou Yacine ${ }^{2}$ \\ ${ }^{1}$ Civil Engineering Department, University of Djelfa, 17000 Djelfa, Algeria \\ ${ }^{2}$ Laboratory of Development in Mechanics and Materials, University of Djelfa, 17000 Djelfa, Algeria
}

Received 10 January 2018; Accepted 19 September 2018

\begin{abstract}
This present work examines the possibility of valorizing the dune sand in the manufacture of mortars having sufficient behaviors to exploit them in the different civil engineering applications. The amelioration of the modified mortars was made by the incorporation of crushed ceramic waste. It was used to replace 5, 10, 15, 20 and $25 \%$ (by weight) of the dune sand in mortar. The results obtained show that the incorporation of the used waste has a significant influence on the behavior of the mortar, in the fresh state and the hardened state. Further to this, it was also observed that the inclusion of the used waste with determined percentages can provide physical and mechanical performances exceed that given by the mortar made with noble sand, which proved its efficiency to the improvement of the different properties of the mortar.
\end{abstract}

Keywords: Dune sand; ceramic waste; mortar; mechanical strength; sulphate resistance.

\section{Introduction}

The valorization of local materials in the manufacture of mortars and concretes is considered among the most effective and least expensive solutions of pollution problems and the abandonment of waste in the environment, as it can also contribute to the reduction of the cost of products for which these materials are part of their compositions, and thus to be able to build less expensive constructions. Among these materials we can mention the dune sand and the various construction wastes.

In areas where dune sand is abundant, this sand imposes itself for its hardness, its cost of extraction and transportation which is very low, and its cleanliness. These characteristics have allowed it to be one of the best solutions to the problems related to the environment and the misuse of noble aggregates resources. Due to the its poor particle size, the studies that have been carried out on its valorization in the different fields of civil engineering, have all aimed to find a way to correct the granular distribution of this sand, with the aim of reducing its porosity, and therefore improve the physical and mechanical characteristics of products whose dune sand is the basic constituent.

The waste of ceramic tiles was produced during manufacturing industry, transportation and placing. The production of these wastes has seen a very significant increase in the world over the past few years. This increase was accompanied by an increase in interest in the valorization of these materials, for the purpose to use them as additives in the production of cements [1], or as active additions in the manufacturing of mortars and concretes $[2,3,4]$. Due to their pozzolanic activity, the use of these wastes in the manufacture of cementitious mixtures can

*E-mail address: ghrieb75@gmail.com

ISSN: 1791-2377 @ 2018 Eastern Macedonia and Thrace Institute of Technology. All rights reserved. doi:10.25103/jestr.114.16 contribute to improving the physical and mechanical properties, reducing the cost, saving energy and protecting the environment [5].

The aim of this work is to valorize ceramic waste as a useful material for correcting dune sand granulometry, with a view to manufacturing mortars with satisfactory performance in terms of consistency, strength and durability. To achieve this objective, a methodology for the formulation of mixtures based on the progressive substitution of dune sand by the studied waste has been adopted. Several tests were then carried out on the mortar mixtures to examine the effect of this waste on the different responses. The results obtained show that the incorporation of the used waste has a significant influence on the behavior of the mortar, in the fresh state and the hardened state. Further to this, it has also been observed that its inclusion with certain percentages makes it possible to obtain performances similar (or even higher) to those of the mortar based on alluvial sand, which demonstrates its effectiveness in improving the various properties of the mortar.

\section{Materials}

\subsection{Cement}

The cement used in this study is of ordinary Portland cement CEM I 42.5. It has been manufactured by the industry group cements of Algeria (GICA). Its specific gravity is $3.11 \mathrm{~g} / \mathrm{cm}^{3}$ and its Blaine surface specific area is equal to $3118 \mathrm{~cm}^{2} / \mathrm{g}$. The potential mineralogical composition of the clinker (Table 1) is calculated according to the empirical formula of Bogue [6].

Table 1. Mineralogical composition of clinker (\%)

\begin{tabular}{cccc}
\hline $\mathrm{C}_{3} \mathrm{~S}$ & $\mathrm{C}_{2} \mathrm{~S}$ & $\mathrm{C}_{3} \mathrm{~A}$ & $\mathrm{C}_{4} \mathrm{AF}$ \\
\hline 52.02 & 28.97 & 6.71 & 12.28 \\
\hline
\end{tabular}




\section{2. Studied sands}

In this work, the experiment was undertaken on two types of sand; a dune sand noted by SD and an alluvial sand designed by AS. The dune sand comes from the dunes of Zaafrane, located about $57 \mathrm{~km}$ northwest of the centre of Djelfa (Algeria). The alluvial sand was taken from the Messaad River, located about 70 Kilometers south of the centre of Djelfa.

The different results of the physical characteristics of the studied sands are summarized in Table 2 . The AS presents a good value of fineness modulus (2.36), however, the DS has a low value (0.86), which means that AS will give a judicious compromise between the workability and the resistance [7]. The sand equivalent test, which is carried out according to NF P 18-598 standard, has given values above the recommended limit for concrete and mortar. This allows the use of AS and DS sands in our investigation.

Table 2. Physical characteristics of the studied materials

\begin{tabular}{lccc}
\hline Physical characteristics & AS & DS & CW \\
\hline Bulk density $\left(\mathrm{g} / \mathrm{cm}^{3}\right)$ & 1.61 & 1.46 & 1.02 \\
Specific density $\left(\mathrm{g} / \mathrm{cm}^{3}\right)$ & 2.60 & 2.53 & 2.43 \\
Porosity (\%) & 38 & 43 & 58 \\
Compactness (\%) & 62 & 57 & 42 \\
Water absorption (\%) & 0.87 & 2.15 & 12.73 \\
Visual sand equivalent (\%) & 81 & 79 & -- \\
Sand equivalent with the piston & 80 & 75 & -- \\
(\%) & & & \\
Maximum size (mm) & 5.00 & 0.63 & 2.50 \\
Fineness modulus & 2.36 & 0.86 & -- \\
Fine particles percentage (\%) & & & 47 \\
\hline
\end{tabular}

The studied dune sand presents a continuous particle size distribution ranging from 0 to $0.63 \mathrm{~mm}$ (Fig. 1). It can clearly be seen that $90 \%$ of grains are lower than $0.3 \mathrm{~mm}$. This sand can be classified from a granular viewpoint as fine sand [8]. The grading is very tight; nearly $90 \%$ of the grains have dimensions ranging between $0.1 \mathrm{~mm}$ and $0.5 \mathrm{~mm}$. The dune sand alone could not have a sufficiently large compactness, and thus not adequate mechanical performances. It should be noted that the considered sand, need therefore to be granularly corrected [9].

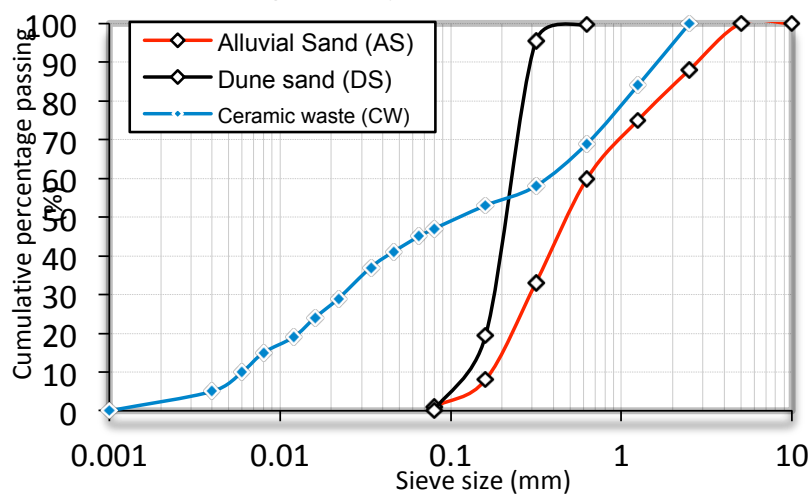

Fig. 1. Particle size distribution of the materials used

The alluvial sand (AS) which is used to make the control mortar, presents a continuous particle size distribution ranging from 0 to $5 \mathrm{~mm}$. Less than $20 \%$ of AS elements are greater than $2 \mathrm{~mm}$ and more than $50 \%$ of the elements greater than $80 \mu \mathrm{m}$ are between 0.2 and $2 \mathrm{~mm}$. According to its grain size, the AS is a medium sand [8].

In this investigation, the X-ray diffraction was conducted with the random powder method for the bulk sample. The results obtained performed by XRD analysis of studied sands demonstrates the essentially siliceous nature of DS and AS sands (Fig. 2).

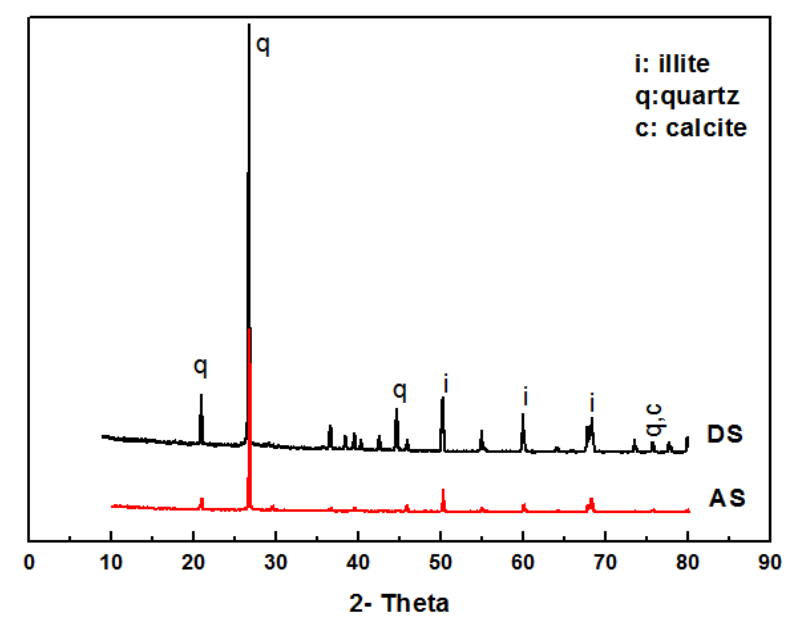

Fig. 2. X-ray diffraction patterns of sands AS and DS

\section{3. Addition (crushed ceramic waste)}

In this study, the used ceramic waste $(\mathrm{CW})$ was supplied from a ceramic tile plant in the region of Setif (Eastern Algeria). The grinding of the studied waste was carried out in laboratory using a ball mill. Table 2 gives its physical properties. The CW particle size distribution (Fig. 1) ranging from 0 to $2.5 \mathrm{~mm}$. The used addition presents relatively lower bulk density and higher water absorption compared to AS and DS aggregates, as can be seen in Table 2. The XRD analysis mentioned in Fig. 3 shows that $\mathrm{CW}$ is comprised of mainly crystalline phase of illite.

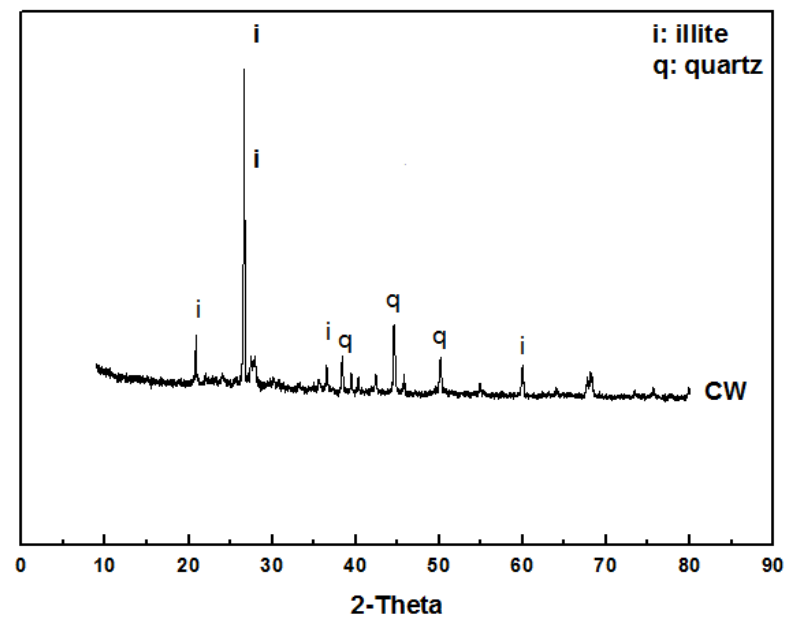

Fig. 3. X-ray diffraction patterns of crushed ceramic waste $(\mathrm{CW})$

\section{Mix proportions and sample preparation}

The mix proportion used to prepare the mortars was the same as used to make the normal mortar, according to the NF EN 196-1 Standard [10]. The addition CW is used as dune sand replacement. In order to study the effect of the waste incorporation on mortar characteristics, the percentages used were $0 \%, 5 \%, 10 \%, 15 \%, 20 \%$ and $25 \%$ by weight of dune sand. A fixed water-cement ratio of 0.70 was utilized for all mixes. Cement-aggregate ratio was 1:3. A reference mix (control mortar) using cement and alluvial sand was prepared, in order to compare it with mortars based on CW. Details of the proportions of mixtures are given in Table 3. 
Table 3. Ponderal composition of designed mortars

\begin{tabular}{|c|c|c|c|c|c|c|}
\hline Symbol of mortar & Mix proportions & Cement (g) & DS (g) & AS (g) & CW (g) & $\mathbf{W} / \mathbf{C}$ \\
\hline MA0 (control mortar) & $100 \% \mathrm{AS}$ & 450 & - & 1350 & - & 0.7 \\
\hline MD0 & $100 \% \mathrm{DS}+0 \% \mathrm{CW}$ & 450 & 1350 & - & - & 0.7 \\
\hline MC5 & $95 \% \mathrm{DS}+5 \% \mathrm{CW}$ & 450 & 1282.5 & - & 67.5 & 0.7 \\
\hline MC10 & $90 \% \mathrm{DS}+10 \% \mathrm{CW}$ & 450 & 1215 & - & 135 & 0.7 \\
\hline MC15 & $85 \% \mathrm{DS}+15 \% \mathrm{CW}$ & 450 & 1147.5 & - & 202.5 & 0.7 \\
\hline MC20 & $80 \% \mathrm{DS}+20 \% \mathrm{CW}$ & 450 & 1080 & - & 270 & 0.7 \\
\hline MC25 & $75 \% \mathrm{DS}+25 \% \mathrm{CW}$ & 450 & 1012.5 & - & 337.5 & 0.7 \\
\hline
\end{tabular}

Upon completion of mixing, the fresh mortar was placed into the molds of dimensions $4 \times 4 \times 16 \mathrm{~cm}^{3}$, they were then clamped onto a vibrating table for $20 \mathrm{~s}$. During the first $24 \mathrm{~h}$, the samples were stored in the normal laboratory environment. After $24 \mathrm{~h}$, these samples were demoulded, and they were then immersed in drinking water at laboratory temperature $\left(23 \pm 2 \mathrm{C}^{\circ}\right)$, until testing.

\section{Testing details}

The workability of fresh mortars was investigated using LCPC maniabilimeter (name of the company: Controlab, model: mortar workability meter, country: France), according to the NF P18-452 standard [11]. The test consists of measuring the time necessary for mortar to flow under the effect of specified vibration until it reaches a reference line. The bulk density of hardened mortars was performed according to the standard NF EN 1015-10 [12]. The mechanical testing of the prepared samples was carried out using an electromechanical universal press (name of the company: Jinan Kason Testing Equipment, model: TLW300, country: China), in accordance with the NF EN 196-1 standard [10]. Mechanical properties were performed on mortar samples of dimensions $4 \times 4 \times 16 \mathrm{~cm}^{3}$ at different curing times 7, 28 and 90 days. The flexural strength was measured using a three point bending test. The halfspecimens resulting from bending test were then subjected to compression on a $4 \times 4 \mathrm{~cm}^{2}$ test section. The water absorption of hardened mortars was performed in accordance with the standard NF EN 1015-18 [13].

The sulfuric acid immersion test was determined on mortar samples of dimensions $4 \times 4 \times 16 \mathrm{~cm}^{3}$, in accordance with the standard ASTM C267 [14], using the 5\% sulfuric acid solution $\left(\mathrm{H}_{2} \mathrm{SO}_{4}\right)$. The masse loss of the mortar samples was monitored at 15, 30, 45, 60, 75 and 90 days after immersion, and the sulfuric acid solution was renewed every 2 weeks.

The sulfuric acid resistance is evaluated by the cumulative percentage of mass loss (CPML), which is given by the following formula:

$\operatorname{CPML}(\%)=\frac{M_{t}-M_{0}}{M_{0}} \times 100$

Where; $M_{t}$ is the mass of the sample at time $t$, and $M_{0}$ is the initial sample mass before immersion in sulfuric acid solution.

\section{Test results and discussion}

\subsection{Workability of mixtures}

The curves of Fig. 4 represent the evolutions of the flow time (workability) according to the quantity added of crushed waste. We notice that, for a fixed water-cement ratio
$(\mathrm{W} / \mathrm{C}=0.7)$, the mixture with dune sand (MD0) exhibits medium workability (16 seconds), however, it is high for the control mortar ( 2 seconds); this is mainly due to the particle size of dune sand which is very fine compared with that of alluvial sand (fine sands require more water ).

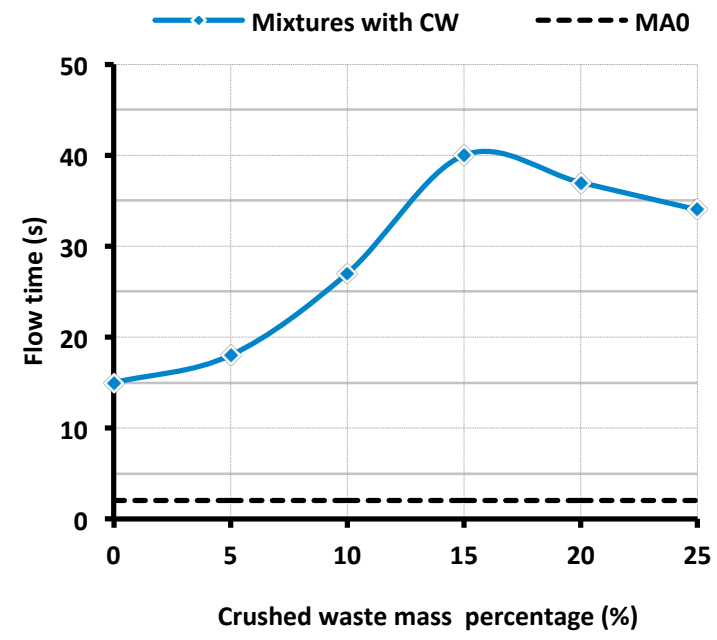

Fig. 4. Evolution of workability as a function of the substitution rate

It was also noted that the progressive substitution of dune sand by $\mathrm{CW}$ addition with percentages of less than $15 \%$, has a significant negative influence on the workability. The work performed by Chaouche $[15,16]$ showed that before voids are entirely filled, the sand grains circulate with difficulty and the low percentage of filler only serves to constrict their movement. Beyond $15 \%$ of $\mathrm{CW}$ addition, the dune sand replacements by used addition have a positive influence on the workability of the fresh mortars. This can be related to the fine fraction of additions filling the voids and releasing the trapped water which consequently improves the consistency of the mortar mixtures [16].

\subsection{Dry bulk density of hardened mortars}

The evolution of dry bulk density of hardened mortars with additions percentage is shown in Fig. 5. It was observed that by increasing of the replacement rate of the crushing waste, the bulk density of the mortars in their hardened state increased until a certain optimum and then decreased. The increase in bulk density for replacement rates from $5 \%$ to $15 \%$ is linked to the decrease of voids volume within the mortars due to the addition of the fine particles [11]; which explains the effectiveness of the used granular corrector (CW) to improve the compactness of the mixtures. At replacement rate equal to $15 \%$, the bulk density of the modified mortars reaches maximum values of $1.92 \mathrm{~g} / \mathrm{cm}^{3}$; these values correspond to optimal filling of the spaces between grains of dune sand [17]. The decrease in bulk density for incorporation percentages beyond $20 \%$ of $\mathrm{CW}$ is 
ascribed to the fine particles which begin to occupy the place of the dune sand grains [16], which increased the overall volume (for the same mass, the volume of the crushed waste is greater than that of dune sand), and consequently, decreased the apparent density of the modified mortars. Finally, let's note that the correction of SD with $15 \%$ to 20 $\% \mathrm{CW}$ makes it possible to obtain bulk densities equal to that of control mortar (MA0).

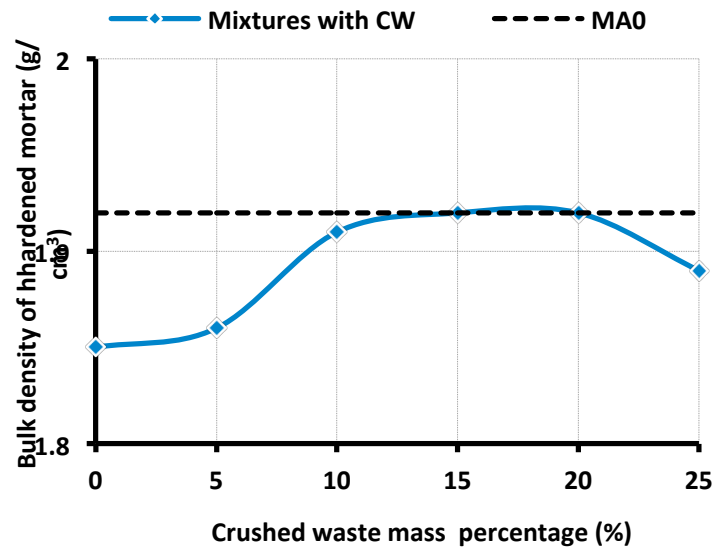

Fig. 5. Evolution in bulk density of hardened mortar versus addition rate

\subsection{Compressive strength}

The development of compressive strength with addition content and with time is given in Fig. 6.a and Fig. 6.b, Many remarks can be formulated about these results;

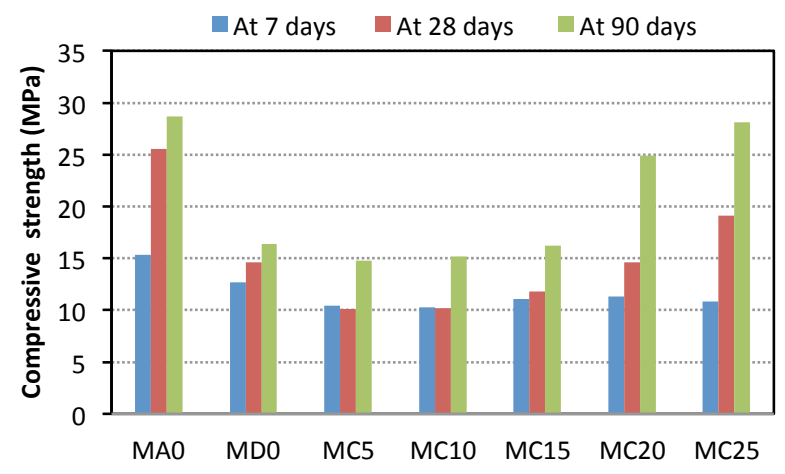

Studied mixtures

(a)

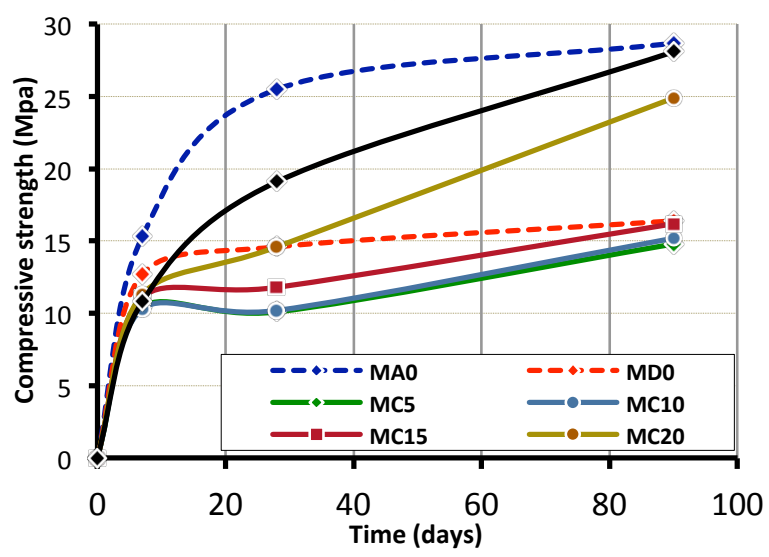

Fig. 6.a) Influence of the incorporation of $\mathrm{CW}$ on compressive strength and b) Evolution of compressive strength over time

At 7 days, the inclusion of $\mathrm{CW}$ as partial replacements of dune sand leads to lower compressive strengths than that of mortar without addition (MD0). As seen in Fig. 7, the use of
$25 \% \mathrm{CW}$ induces a loss in compressive strength of $15 \%$. This results show that, at this age, the use of the studied addition has significantly delayed cement hydration (chemical effect) and consequently decreased the compressive strength of mortars.

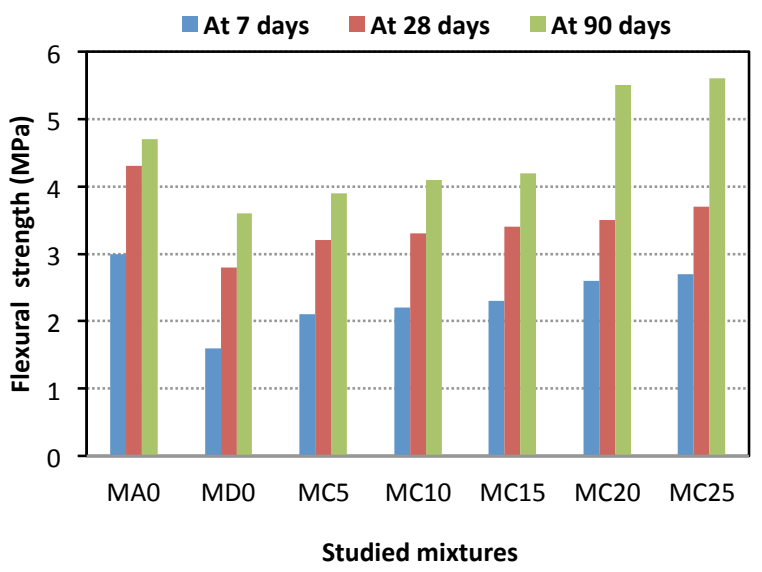

Fig. 7. Influence of the incorporation of $\mathrm{CW}$ on flexural strength

At 28 days, the increase in $\mathrm{CW}$ content leads to a continuous increase in the compressive strength. This shows that the chemical effect of $\mathrm{CW}$ on the evolution of compressive strength due to its possible pozzolanic reactivity is most dominant, because its filling effect normally leads to a maximum strength between $15 \%$ and $20 \%$ of $\mathrm{CW}$ (the percentages for which the compactness is maximum (Fig. 5)). This is in agreement with the results of previous research works $[1,4]$.

We can also add that the compressive strength does not reach that of the mortar without addition (MD0) that as from $20 \% \mathrm{CW}$, and the incorporation of $25 \% \mathrm{CW}$ induces a gain in compressive strength of $30.8 \%$.

At 90 days, the same remark may be noted concerning the evolution of the compressive strength as a function of the percentage of $\mathrm{CW}$, Which remains an increasing function. We also notice that the use of $\mathrm{CW}$ as a dune sand substitute becomes effective only from $20 \%$ of $\mathrm{CW}$. The strength gain rate is of the order of $50 \%$ and $70 \%$ for $20 \%$ and $25 \%$ of $\mathrm{CW}$ respectively. The incorporation of $25 \% \mathrm{CW}$ can gives maximum improvement which makes it possible to reach compressive strength close to that of the control mortar (MA0). These results clearly indicate the effectiveness of the crushed ceramic waste in improving the compressive strength of the SD-based mortars.

Finally, it is found that the effect of $\mathrm{CW}$ on the evolution of compressive strength as a function of time is very significant (Fig. 6.b), especially after 28 days. Where it is found that the rate of increase in compressive strength from 28 days to 90 days for mortars without additions (MA0 and MD0) is about $12 \%$, whereas, it is $70 \%$ and $47 \%$ for $20 \%$ and $25 \%$ of $\mathrm{CW}$ respectively; this can be attributed to the pozzolanic activity which becomes important after 28 days.

\subsection{Flexural strength}

The flexural strength results of mortars mixes made with and without $\mathrm{CW}$ were given in Fig. 7. From these results, it can be seen that the flexural strength of $\mathrm{CW}$ mortars, were higher than the mortar without addition (MD0) at all ages. It is evident from Fig. 8 that this characteristic increases continuously until reaching its maximum value at $25 \% \mathrm{CW}$, with rate of increase of strength about $69 \%, 32 \%$ and $56 \%$ at 7 days, 28 days and 90 days respectively. 


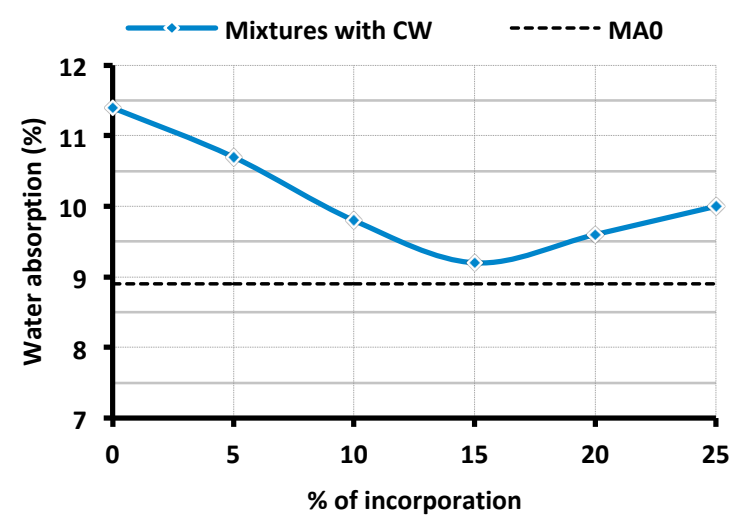

Fig. 8. Effect of addition amount on water absorption

The inclusion of $\mathrm{CW}$ as a partial replacement of dune sand makes it possible to achieve flexural strengths at 90 days higher than that of the control mortar (MA0); the 90days strengths for $20 \%$ and $25 \% \mathrm{CW}$ exceed that of the control mortar by $17 \%, 19 \%$ respectively. These values vividly demonstrate the effectiveness of used additions in improving the flexural strength of the dune sand mortars. These results agree with those of other authors [1, 4], who report that the incorporation of ceramic waste material improved the mechanical strength of mortars.

\subsection{Water absorption of hardened mortars}

The results of water absorption of the mortar mixes are shown in Fig. 8. It was observed that by increasing the rate of CW incorporation, the water absorption coefficient of the mortars decreased until $15 \%$ and then increased. J. Silva et al. [4] concluded that the decrease of the absorption coefficient with the incorporated ceramic waste ratio is attributed to the existence of less internal voids within the hardened mortars due to the fines addition, thus providing thinner capillary vessels and a smaller water flux within the mortar. The increase of this characteristic can be related to the increase of the quantity of free water in the mixtures after the filling of the voids. The value of the absorption coefficient at $15 \% \mathrm{CW}$ (Fig. 8) means that the porosity of the mixture MC15 is the lowest (the compactness is the highest), which confirms the results of the other tests (workability, bulk density of hardened mortars).

\subsection{Resistance to sulfuric acid attack}

The mass loss is commonly used as acceptable indicator to evaluate the deterioration of mortars and concretes under acid attack [18, 19]. Fig. 11 represent the mass loss (negative means mass loss) of specimens exposed to sulfuric acid up to 90 days. From these results, it can be observed that the mass is gradually decreased with the increase in exposure time for all studied mortars. This deterioration of mortar structure is mainly caused by the reaction between calcium hydroxide $\left(\mathrm{Ca}(\mathrm{OH})_{2}\right)$ presented in cement and the sulfuric acid, which can induce tensile stress, resulting in cracking and scaling of mortar [20].

As shown in Fig. 9, the replacement of part of dune sand by CW increased the mortar's ability to resist to acid attack. The mortar containing 10\% of $\mathrm{CW}$ (MC10) can give the same acid resistance as that of control mortar. Beyond $15 \%$ the $\mathrm{CW}$ mortars exhibited higher acid resistance than that of control mortar. At the end of the test period, the incorporation of $25 \% \mathrm{CW}$ causes an improvement in acid resistance about $40 \%$.

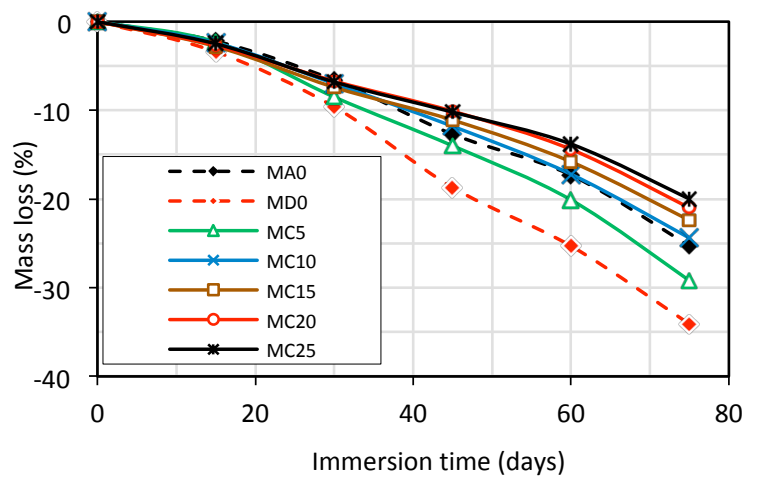

Fig. 9. Mass loss of mortar samples due to immersion in sulfuric acid solution

The visual inspection of mortars having undergone chemical attack in contact with sulfuric acid is a means to evaluate the deterioration of the physical properties and the deteriorations of the external appearance of the test pieces, and to confirm and compare the results obtained.

The state of most samples with and without added addition, after a storage period of 90 days, is characterized at first sight by a reduction in volume and a color change compared with samples stored in water. Fig. 10

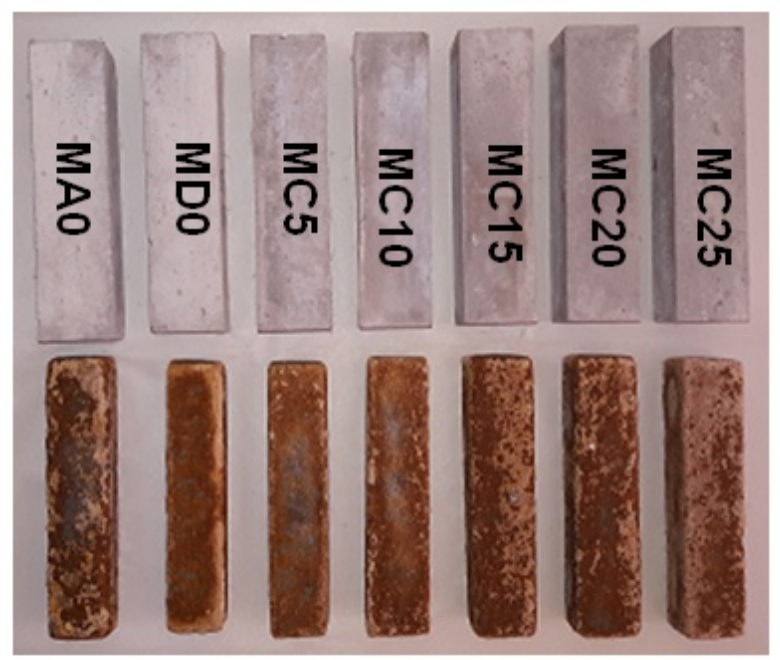

Fig. 10. Deterioration of mortar samples after 90 days of immersion in $5 \% \mathrm{H}_{2} \mathrm{SO}_{4}$ solution

\section{Conclusion}

This study was conducted to assess the possibility of utilizing crashed waste of ceramic tiles $(\mathrm{CW})$ as a partial replacement of dune sand, and of valorizing them in mortar manufacturing. Based on the results of the experimental program conducted in this investigation, the following main conclusions could be pinched:

- For fixed W/C ratio, the progressive substitution of dune sand by $\mathrm{CW}$ addition with percentages of less than $15 \%$, has a significant negative influence on the workability, however, beyond $15 \%$, it has a positive effect.

- The optimal filling of the voids between grains of dune sand, which corresponds to maximum compactness and bulk density, is obtained for CW content between $15 \%$ and $20 \%$.

- The use of CW as a partial replacement of dune sand can give very good improvements in compressive strength at 90 days; about $70 \%$ for $25 \% \mathrm{CW}$. These improvements make it possible to reach compressive strength close to that of the 
control mortar. The effect of the inclusion of the crushed ceramic waste on the evolution of compressive strength with time is very significant, especially after 28 days; this is mainly attributed to the pozzolanic activity which becomes important in this period.

- The correction of dune sand with 20 and $25 \% \mathrm{CW}$ allows obtaining flexural strengths at 90 days higher than that of the control mortar (MA0); the 90 -days strength at $25 \%$ of $\mathrm{CW}$ exceed that of the control mortar by $19 \%$; this reflects the efficiency of the crushed ceramic waste to improve this characteristic.

- The addition of CW increased the mortar's ability to resist to acid attack. Beyond incorporation rate of $15 \%$ the $\mathrm{CW}$ mortars exhibited higher resistance to sulfuric acid attack than that of mortar based on alluvial sand.

This is an Open Access article distributed under the terms of the Creative Commons Attribution License

\section{References}

[1] Ay N, Ünal M. The use of waste ceramic tile in cement production. Cement and Concrete Research. 2000; 30: 497-499.

[2] Abadou Y, Mitiche-Kettab R, Ghrieb A. Ceramic waste influence on dune sand mortar performance. Construction and Building Materials. 2016; 125: 703-713.

[3] Binici H. Effect of crushed ceramic and basaltic pumice as fine aggregates on concrete mortars properties. Construction and Building Materials. 2007; 21: 1191-1197.

[4] Silva J, De Brito J, Veiga R. Incorporation of fine ceramics in mortars. Construction and Building Materials. 2009; 23: 556-564.

[5] Pašalić S, Vučetić S, Zorić D, Ducman V, Ranogajec J. Pozzolanic mortars based on waste building materials for the restoration of historical buildings. Chemical Industry and Chemical Engineering Quarterly. 2012; 18 (2): 147-154.

[6] Bogue R.H. Chemistry of Portland cement. New York (NY): Reinhold Publishing; 1955.

[7] Dreux G, Festa J. Nouveau guide du béton et de ses constituants. France : Eyrolles; 1998.

[8] Chauvin JJ. Les sables, guide technique d'utilisation routière. France : ISTED; 1987.

[9] Ghrieb A, Mitiche-Kettab R, Bali A. Stabilization and utilization of dune sand in road engineering. Arab J Sci Eng. 2014; 39 (3): 1517 1529.

[10] AFNOR standards organisation. Méthodes d'essais des ciments Partie 1 : détermination des résistances mécaniques. NF EN 196-1; 2006.

[11] AFNOR standards organisation. Bétons - Mesure du temps d'écoulement des bétons et des mortiers aux maniabilimètres NF $18-452 ; 1988$
[12] AFNOR standards organisation. Méthodes d'essai des mortiers pour maçonnerie - Partie 10 : détermination de la masse volumique apparente sèche du mortier durci. NF EN 1015-10;2000.

[13] AFNOR standards organisation. Méthodes d'essai des mortiers pour maçonnerie - Partie 18 : détermination du coefficient d'absorption d'eau par capillarité du mortier durci. NF EN 1015-18; 2003.

[14] American Society for Testing and Materials (ASTM) C 267. Standard test methods for chemical resistance of mortars, grouts, and monolithic surfacings and polymer concretes. ASTM C267; 2003.

[15] A.A. Chaouche, A. Bali. Etude des caractéristiques des bétons de sable de dune. Thesis of Magister. Ecole Nationale Polytechnique d'Alger. 1993, Algérie. (in French).

[16] Bédérina M, Khenfer MM, Dheilly RM. Quéneudec M. Reuse of local sand: effect of limestone filler proportion on the rheological and mechanical properties of different sand concretes, Cem. Concr. Res. 2005; 35: 1172-1179.

[17] Chauvin JJ, Grimaldi G, Les bétons de sable, Bull. Liaison Lab. Ponts et Chausseés. 1988; 157: 9-15.

[18] Attiogbe KE, Rizkallah HS. Response of concrete to sulphuric acid attack. ACI Materials Journal. 1988; 85 (6): 481-488.

[19 Fattuhi NI, Hughes BP. SRPC and modified concretes subjected to severe sulphuric acid attack. Magazine of Concrete Research. 1988; 40 (144): 159-166.

[20] Sata V, Sathonsaowaphak A, Chindaprasirt P. Resistance of lignite bottom ash geopolymer mortar to sulfate and sulfuric acid attack. Cement and Concrete Composites. 2012, 34: 700-708. 